\title{
Nurses' experiences of the role of organizational and environmental factors in the development of love of the profession: a qualitative study
}

Mohsen Adib-Hajbaghery

Kashan University of Medical Sciences

Shahnaz Bolandian-Bafghi ( $\sim$ sh.bolandian@yahoo.com )

Kashan University of Medical Sciences

Mitra Zandi

Shahid Beheshti University of Medical Sciences

\section{Research Article}

Keywords: Content analysis, love, Love of the profession, Nurse, Nursing profession, Qualitative study

Posted Date: November 30th, 2021

DOI: https://doi.org/10.21203/rs.3.rs-1101147/v1

License: (c) (i) This work is licensed under a Creative Commons Attribution 4.0 International License.

Read Full License 


\section{Abstract \\ Background}

Love of the profession has significant relationship with nurses' job motivation and care quality. However, there is limited information about organizational and environmental factors affecting LOP among nurses.

\section{Aim}

This study aimed at exploring nurses' experiences of the role of organizational and environmental factors in the development of Love of the profession.

\section{Methods}

This qualitative study was conducted in 2020-2021 using the conventional content analysis approach. Participants were Fifteen Iranian nurses with deep Love of the profession, nursing instructors, and nursing managers purposefully selected from different healthcare and academic settings in seven large cities of Iran. Data were gathered via semi-structured interviews and were analyzed via the conventional content analysis method proposed by Graneheim and Lundman.

\section{Results}

Organizational and environmental factors affecting the development of Love of the profession were grouped into three main categories, The social context of the profession (with two subcategories), family support (with two subcategories), and organizational health (with four subcategories). Subcategories were respectively historical context of the profession, the evolving context, emotional family support, instrumental family support, quality of interpersonal relationships in the organization, level of organizational justice, level of authority delegation to nurses, and level of organizational support.

\section{Conclusions}

Different organizational and environmental factors can affect nurses' Love of the profession development. Improving public image of nursing, providing nurses with stronger support, improving organizational climate, and strengthening interpersonal relationships in healthcare settings are recommended to develop nurses' Love of the profession.

\section{Introduction}


Nursing is currently considered as a profession because nurses have autonomy, professional commitment, specialty, knowledge and skills, value system, and academic education (1). The presence of values is one of the key characteristics of nursing that turns it into a profession (2). Florence Nightingale, the founder of modern nursing, states that nursing is not a scientific knowledge and a technical skill; rather, it is a profession that is based on human values $(3,4)$ such as love for human beings and for providing care to them (5). She also highlights that this love for human beings is the base of love of the profession (LOP) among nurses (6). LOP brings values, power, and beauty to the life of nurses and their clients and hence, is considered as one of the most important principles of nursing (7).

There are many different definitions for LOP. Some scholars described LOP as feelings of interest, concern, respect, understanding, responsibility, benevolence, altruism, and dedication. Some scholars also used LOP-related concepts, such as work engagement, to define LOP, while work engagement is a positive subjective approach to the profession characterized by attributes such as power, dedication, and absorption $(8,9)$.

Irrespective of its definition, LOP has different effects on both nurses and their clients. It deepens nurses' understanding of patients and their sufferings(10), guides nurses' behaviors and actions, improves the quality of their care services, facilitates patient recovery, and enhances patient satisfaction (11). Nurses with LOP use their whole physical, cognitive, and emotional abilities at work, while limited LOP is associated with the separation of physical, cognitive, and emotional abilities from professional activities and the separation of nurses from their professional roles (6).

Although nursing textbooks emphasize care based on the nursing process, in clinical

education, Iranian students are generally trained in a traditional and task-oriented man-

ner, and are mainly prepared to carry out physicians' orders (12). Therefore, nursing is physician-based, and a pivot routine is one of the most important characteristics of Iranian nurses (13). The reasons mentioned above generally demotivate most nurses and make

them less interested in their profession.

Earlier, we examined the factors contributing to the development of the LOP and have reported that the public perception of the profession, educational variables, characteristics of the profession, and nurses' self-evaluation effectively develop the LOP in nurses. Although in that report several nurses cited the impact of social factors on the development of the LOP (14). However, the environmental and organizational factors affecting the development of LOP in nurses have not been assessed. The findings of this study raise the question for researchers that apart from the profession's public image, whether or not other environmental and social factors affect the LOP in nurses. The previous study's findings only emphasize the effect of society's public image on love of the profession and have no answers to the questions above. Therefore, the present study tries to elucidate these factors. Due to the possibility of overlapping findings with the previous study preventing it, the researchers tried to limit their questions to 
the influences of environmental and organizational factors and examin their impact on the profession's love. Inaddition, they tried to involve more participants in the study and examine their experiences.

To the best of our knowledge, none of the previous studies explored factors affecting LOP, particularly organizational and environmental factors. Most studies in this area explored factors affecting LOPrelated concepts such as work engagement. For example, a study showed that $37 \%$ of students developed interest in nursing due to environmental factors (15). Another study reported that work-family enrichment improved nurses' mood, reduced their perceived stress, increased their resistance to stressors, and thereby, enhanced their job satisfaction and lowered their turnover rate (16). A study also showed that transformational leadership and structural empowerment were the significant predictors of nurses' work engagement (17). Similarly, a study reported that nursing managers had significant roles in improving nurses' work engagement, while payments and benefits were not the principal factors in nurses' work engagement (18).

Given the paucity of information about factors affecting LOP, the present study was conducted to narrow this gap.

\section{Aim of the Study}

The aim of the study was to explore nurses' experiences of the role of organizational and environmental factors in the development of LOP.

\section{Methods}

This qualitative content analysis study was conducted in 2020-2021 using the conventional content analysis approach. In qualitative content analysis, manifest and latent concepts are extracted from participants' descriptions and then are coded, abstracted, and categorized to develop main categories or themes (19).

\subsection{Participants}

Participants were Iranian nurses with deep LOP, nursing instructors, and nursing managers. They were purposefully selected from different healthcare settings and universities in seven cities of Iran, namely Yazd, Isfahan, Kashan, Tehran, Mashhad, Birjand, and Kerman. Sampling was performed with maximum variation in order to include a wide range of experiences and viewpoints in the study. The inclusion criteria were a desire to attend the study, clinical work experienceof at least two years, popularity as a nurse with deep LOP among colleagues, the ability to share LOP-related experiences, having a good way with words, and being able to share their experiences in detail. For this purpose, nurses who were witty with the ability to express themselves properly were meant be included in the study. Having explained the objectives of the research to the nurse managers, they were asked to introduce those nurses who are enthusiastic and love their profession. They introduced such nurses to the researcher with respect to characteristics they believed are the key to choose: a sense of responsibility, high performance, proper 
behavior, resilience, passion and a sense of initiation. The participants were also asked to introduce someone they knew who loved the profession. Before the researcher started the main study, the interview guide was pilot-tested on two nurses to ensure the consistency of the questions' meanings, and that the questions were clear and comprehensible. These two nurses did not participate in the main study, and their interviews were discarded.

\subsection{Data collection}

In-depth semi-structured interviews were conducted to collect the data. Initially, some broad questions were used to establish appropriate communication with participants and gain their trust. Then, the following questions were used for data collection, "Have environmental factors affected your LOP?" and "Can you explain about your experiences of the effects of environmental factors on your LOP?" Moreover, questions such as "May you explain more?" and "What led to this?" were used to encourage participants to provide more details about their experiences. The place and the time of interviews were arranged according to participants' preferences and all interviews were conducted in their lounge. Interviews were held by the second author, lasted 30-90 minutes, and were continued up to data saturation. Saturation was ensured when no new conceptual codes were obtained from interviews and all aspects of organizational and environmental factors were explored (20). A second interview was conducted with some of the participants if theresearcher encountered any ambiguities or questions while reading and analyzing the interviews. In this way, participants number 1, 2, 3 and 13 were interviewed twice. Saturation was achieved after Nineteen interviews with Fifteen participants. All interviews were audiorecorded using an MP3 player.

\subsection{Data analysis}

Data were analyzed via the conventional content analysis method proposed by Graneheim and Lundman(21). Each interview was listened to for several times and was transcribed word by word using the Microsoft Word. Then, each interview was considered as the unit of analysis and was perused several times to immerse in the data. Thereafter, important words and sentences which were relevant to the study aim were identified and coded and the codes were categorized according to their similarities. Developed categories were revised, further developed, and combined with each other during the analysis of each new interview and thereby, main subcategories and categories were identified. Data analysis was managed via the MAXQDA 10 software.

\subsection{Trustworthiness}

Trustworthiness was established using the criteria proposed by Guba and Lincoln, namely credibility, dependability, confirmability, and transferability $(20,22)$. Credibility was established through member checking, peer checking, prolonged engagement with the data, immersion in the data, and sampling with maximum variation. Dependability was also established through peer checking. In peer checking, three nursing scholars external to the study with considerable experience in qualitative research assessed and confirmed the accuracy of data analysis. Transferability was ensured through providing thick 
descriptions of the processes of data collection and analysis. Moreover, two nurses with LOP who were external to the study were asked to assess the similarity between our findings and their own experiences. They confirmed that our findings were similar to their experiences. In addition, COREQ checklist was used to evaluate and report the study.

\section{Findings}

Participants were nine female and Six male nurses with LOP, nursing instructors, and nursing managers. The range of their age and work experience was 30-59 and 7-30 years, respectively. Four participants had master's degree and the remaining ten participants had bachelor's degree. Six participants were hospital nurses, two were head nurses, two were supervisors, two were nursing instructors, one was infection control staff, one was relief staff and one was manager. All of them had clinical work experience and four of them had the experience of teaching to nursing students. Table 1 shows participants' characteristics.

Table 1

Participants' demographic characteristics

\begin{tabular}{|c|c|c|c|}
\hline \multicolumn{2}{|c|}{ Demographic characteristics } & \multirow{2}{*}{$\begin{array}{l}\text { Frequency } \\
6\end{array}$} & \multirow{2}{*}{$\begin{array}{l}\text { Percent } \\
40 \%\end{array}$} \\
\hline Gender & Male & & \\
\hline & Female & 9 & $60 \%$ \\
\hline \multirow[t]{3}{*}{ Age(year) } & \35 years & 2 & $13.3 \%$ \\
\hline & 35- 45 years & 7 & $46 / 6 \%$ \\
\hline & $₫ 45$ years & 6 & $40 \%$ \\
\hline \multirow[t]{2}{*}{ Degree } & Bachelor's & 11 & $73 / 3 \%$ \\
\hline & Master's & 4 & $26 / 6 \%$ \\
\hline \multirow[t]{4}{*}{ Work experience (Years) } & $\nabla 10$ years & 2 & $13 / 3 \%$ \\
\hline & $10-15$ years & 3 & $20 \%$ \\
\hline & ه15 years & 10 & $66 / 6 \%$ \\
\hline & Total & 13 & $100 \%$ \\
\hline
\end{tabular}

In total, 109 conceptual codes were generated during data analysis which were categorized into eight subcategories and three main categories. The main categories were The social context of the profession, family support, and organizational health (Table 2). 
Table 2

The main categories and subcategories of organizational and environmental factors in love of profession development

\begin{tabular}{|ll|}
\hline Main Categories & Subcategories \\
\hline The social context of the profession & $\begin{array}{l}\text { Historical context of the profession } \\
\text { Family support }\end{array}$ \\
\hline Organizational health & $\begin{array}{l}\text { Emotional family support } \\
\text { Instrumental family support }\end{array}$ \\
\hline $\begin{array}{l}\text { Quality of interpersonal relationships in theorganization } \\
\text { level of organizational justice }\end{array}$ \\
\hline $\begin{array}{l}\text { Level of authority delegation to nurses } \\
\text { Level of organizational support }\end{array}$ \\
\hline
\end{tabular}

3.1. The social context of the profession

The social context of the profession was one of the main environmental factors affecting LOP development. It reflects how the nursing appears to people and what mental idias or pictures the public have about it. The two subcategories of this category were historical context of the profession and the evolving context.

\subsubsection{Historical context of the profession}

The historical context of the profession refers to the common view of society in the nursing profession. This context and the quality of public respect for nursing can considerably affect nurses' LOP. Our participants noted that they felt deeper LOP whenever they were respected and valued for their profession. Contrarily, stereotypical or negative images of nursing negatively affected their LOP. They reported culture, religion, and tradition in the community as a compelling social context for creating and developing a profession's love.

People respected me whenever they found I am a nurse. This increased my interest in nursing (P. 10).

I had many good suitors. However, all of them changed their minds when I entered nursing. Why? Because they had a poor image of nursing. They believed that nurses are shameless. Such things cause me not to love nursing a lot (P. 14).

\subsubsection{The evolving context}

Participants noted that significant events such as war, earthquake, and the coronavirus 2019 (COVID-19) pandemic have suddenly changed the public image and value of nursing. They noted that nurses' dedication to saving veterans' lives during the war, earthquake victims, and patients' lives during the 
COVID-19 pandemic had significant positive effects on society's view of the profession and has caused a sudden change in society towards the nursing profession.

Nurses' attempt to save veterans' lives changed public image of nursing and hence, people no longer have negative image or attitude towards nursing (P. 5).

Public mind-set towards us has considerably improved after the prevalence of the COVID-19. People's respect for us has made me have better feelings towards nursing (P. 9).

\subsection{Family support}

The experiences of some participants showed that family had significant effects on their LOP. Family support for them caused them not to feel loneliness in the midst of their responsibilities. Strong family support fostered in participants the belief that their profession as well as themselves were accepted by family members and gave them sense of worthiness. Moreover, family support increased their success in professional and familial affairs and thereby, improved their work engagement. This category had two subcategories, namely emotional family support and instrumental family support.

\subsubsection{Emotional family support}

Nursing, particularly clinical nursing, is a difficult profession due to different work shifts, long work hours, and heavy workload. Therefore, nurses need strong support to be able to effectively perform their professional roles. The experiences of some participants showed that they had such support. Emotional support by family increased participants' professional and familial success and thereby, improved their job motivation, professional self-image, professional interest, and LOP. The different aspects of emotional family support were feeling proud of a nurse family member, husband's good attitude towards nursing, and family encouragement, acceptance, and understanding.

My husband has a very good attitude towards nursing. He is just like me. He says that nursing is your job, your duty, the thing that you was interested in and studied for it. He considers me important for society ( $P$. 1).

However, the experiences of some participants showed that their families not only had no good attitude towards nursing, but also encouraged them to quit the profession.

My family members don't accept nursing at all and recommend me to quit it (P. 14).

\subsubsection{Instrumental family support}

Multiple familial and professional responsibilities, particularly among female nurses, together with others' expectations exert significant physical and mental effects on nurses. Our participants' experiences showed that instrumental support by family reduced their role conflicts, fatigue, and strain, improved their energy for professional activities, increased their professional success, and thereby, fostered greater LOP 
among them. The different types of instrumental support by family members were help in childrearing, help in children's school affairs, and help in performing household activities.

My husband has arranged his work hours according to my work hours so that he takes care of children when I'm at work. Therefore, I have no concern over children and do my job with greater concentration (P. 7).

\subsection{Organizational health}

Organizational health and suitability can also affect LOP among nurses. Participants' experiences showed that interpersonal relationships in the organization, organizational justice, personal power and autonomy in organization, and organizational support for staff had significant roles in developing their LOP. The four subcategories of this category were the quality of interpersonal relationships in the organization, level of organizational justice, level of authority delegation to nurses, and level of organizational support.

\subsubsection{Quality of interpersonal relationships in the organization}

Some participants highlighted that a friendly organizational atmosphere and appropriate interpersonal communications at work provide nurses with better feelings and greater peace.

The work atmosphere in our setting was very friendly when I started my work. For example, our head nurse had a very good conduct. This increased my interest (P. 3).

On the other hand, paternalistic approach of authorities can reduce positive emotions in theworkplace and thereby, reduce nurses' interest in work.

Some authorities treat nurses, particularly novice nurses, as they are soldiers at a military base. Instead of a rigid conduct from the very beginning, we need to make novice nurses interested in work (P. 8).

\subsubsection{Level of organizational justice}

Most participants reported organizational justice as an influential factor on LOP. Fair payments, competence-based appointments, and no discrimination among nurses can bring nurses senses of peace, security, and justice, gain nurses' trust in organization, promote their professional and organizational commitment, and foster their LOP.

Justice, non-discrimination, and competence-based career advancement in theorganization increase our professional interest (P. 10).

Injustice is the most disturbing thing for nurses. For example, during this COVID-19 pandemic, a doctor visits a patient just for half an hour and receives the salary of twelve hours work of a nurse for such visit. Such injustice reduces nurses' motivation (P. 6). 


\subsubsection{Level of authority delegation to nurses}

The level of authority delegation to nurses was another organizational factor affecting LOP. By authority delegation, participants meant autonomy at work, decision making power, latitude, and the right to freely share ideas. Participants noted that based on their professional knowledge and skills, nurses need autonomy and latitude at work and highlighted that autonomy and latitude give nurses sense of power and self-confidence and increase their motivation for professional practice.

Greater autonomy and latitude for nurses reduce their dependence on physicians, give them sense of power, and help them work more independently, which in turn improve their interest and motivation (P. 9).

Contrarily, authorities' paternalistic behaviors and nurses' limited perceived autonomy and power give nurses sense of oppression and reduce their job motivation and interest in profession and organization.

The approach of the Ministry of Health is paternalistic, in which power is with physicians. Violation of nurses' rights in this system reduces their motivation (P. 6).

\subsubsection{Level of organizational support}

According to the participants, organizational support can also affect nurses' LOP. They noted that as staff of an organization establish emotional relationship with their organization, the level of tangible and intangible support by their organization and managers can affect their LOP and professional interest.

I was on a long evening-night shift. We had a critically-ill patient and were involved with the patient up to 06:00. I was extremely tired. My colleagues suggested me to take a rest. I took a rest from 06:00 to 06:30. This is not a legal time for rest in our hospital. When I returned the ward at 06:30, my colleagues said that the matron of hospital had been in the ward and considered a reward for me for that busy shift. Such value attachment to my work was very important to me. My manager did not criticize me for being on rest in an illegal time. This motivates staff and increases their belongingness to work (P. 4).

On the other hand, lack of organizational support can reduce LOP.

When they assigned me night shifts, I told them I couldn't work at night and asked them to reduce the number of my night shifts. However, they refused. Nobody understood me (P. 14).

\section{Discussion}

This study explored nurses' experiences of the role of organizational and environmental factors in LOP development. Therefore, it can be claimed that this study is one of the few studies performed in the field of LOP in nurses. Participants' experiences showed that the main organizational and environmental factors in LOP development among nurses were the social context of the profession, family support, and organizational health. 
The social context of the profession was one of the main environmental factors in developing LOP. The social context of the profession indicates the ideas people have about nursing and affect the level of public respect for nursing and public understanding about it. In line with this finding, former studies reported that the social status of nursing significantly affects its development, social respect for it (23), nurses' job motivation their job satisfaction, and their $\operatorname{LOP}(24,25)$. However, our participants were dissatisfied with stereotypical images of nursing and considered them as factors with negative effects on their job motivation and professional interest. Even after many years of men's entrance in nursing, most people in Iran consider nursing as an inappropriate profession for men. This attitude negatively affects men's motivation to enter nursing (26). Similarly, a study in East Africa showed that despite improvements in the public image of nursing, some people still believed that nurses were rude, cruel, thieve, and handmaiden (27). Nonetheless, we found that significant events such as war, earthquake, and the COVID-19 pandemic can affect public attitude and social context towards nursing. Two previous studies also reported significant improvements in public attitude towards nursing after wars $(28,29)$. During the COVID-19 pandemic, people around the world also admired nurses, appreciated their practice, and showed love for them (30), which resulted in positive feelings such as proud and honor among nurses (31).

The second main factor in LOP development among nurses was family support. Previous studies also reported that nurses' familial problems and limited family support can negatively affect their professional practice, job satisfaction, and job motivation $(32,33)$, and highlighted the significant positive effects of emotional and instrumental support by family members on nurses' performance at home and work (34). These findings denote that family support facilitate LOP development, while limited family support can result in family-work conflicts, low job motivation, and intention to quit nursing.

Organizational health was the third main factor in LOP development. Our findings showed that interpersonal relationships at work, organizational justice, organizational support, and the level of authority delegation to nurses were the main organizational factors affecting nurses' LOP. A supportive work environment can reduce nurses' role ambiguities, empower them to use their skills and establish effective interpersonal relationships with their colleagues, make them value non-material aspects of work more than its material aspects, and improve their professional commitment and job satisfaction (35). Nurses' effective interactions with each other and with their managers significantly improve their organizational attachment $(36,37)$. Moreover, organizational support, friendly atmosphere at work, and close relationships with colleagues have significant positive relationships with nurses' work engagement (38). A study also reported that leader-nurse interaction had significant relationship with nurses' organizational commitment, professional practice(39), and work engagement (40). Another study showed that organizational support had significant effects on healthcare workers' organizational attachment and their intention to leave their professions (19). Similarly, a study found that workplace empowerment had significant positive effects on nurses' practice, behaviors, organizational commitment, and work engagement (4). Furthermore, a study showed lower ambiguities, higher staff morale and productivity, greater organizational commitment and professional interest, and lower staff turnover in healthy organizations(41). All these findings confirm the significant effects of organizational characteristics on 
LOP. Nonetheless, there is no consensus over the effects of organizational factors on nurses. For example, a study found that salaries and benefits were not among the main predictors of work engagement(42). Another study showed that nurse-peer interaction had no significant relationship with nurses' professional practice (19). These contradictions are attributable to the differences among studies respecting their settings, designs, and participants.

\section{Implications for nursing and health policy}

Identifying the organizational-environmental factors behind the development of love for the nursing profession would help health care policymakers manipulate these factors and develop love and commitment toward their profession in nurses. The development of love for the profession in nurses will increase their professional commitment and the quality of nursing services, reduce their turnover, and ultimately, will improve the position of the nursing profession in society, as well as the level of public health.

\section{Conclusion}

This study concludes that LOP development among nurses is affected by different organizational and environmental factors, The social context of the profession, family support, and organizational health. Therefore, strategies such as correcting stereotypical public images of nursing, improving public status of nursing, providing nurses with stronger familial, organizational, and social support, improving organizational climate,and strengthening interpersonal relationships in healthcare organizations are recommended to improve nurses' job satisfaction and motivation and develop their LOP. LOP development can in turn improve the quality of nursing care and positively affect public health.

\section{Recommendations}

Future studies are recommended to develop and assess the effects of LOP development strategies. Moreover, given the positive effects of the COVID-19 pandemic on public attitude towards nursing, qualitative studies are needed to further explore the effects of this pandemic on nurses' LOP.

\section{Limitations}

Although we attempted to establish effective communication with participants, some of them might have had some considerations in sharing their experiences with us, for which the researcher should seek to gain the participants' trust by communicating effectively and removing this barrier insofar as is possible. Moreover, despite nurses' great interest in our study, some of them(3 nurses) refused participation due to factors such as the risk of COVID-19 transmission, heavy workload, concerns over childrearing and their children's education, and fatigue.The findings of this work might also be affectedby gender, as a large number of female nurses participated in the study. However, this is due to the large number of female nurses in Iran. 


\section{Abbreviations}

Love of the profession (LOP)

\section{Declarations}

\section{Ethics approval and consent to participate}

The research ethics committee of Kashan University of Medical Sciences, Kashan, Iran, approved the study (code:IR.KAUMS.NUHEPM.REC.1398.058. approval date.2019.12.21. grant number :98175). Participation in the study was voluntary and participants were free to unilaterally withdraw from the study. Participants were provided with explanations about the study aim, data confidentiality, honesty in reporting the findings, and use of their data solely for the purposes of this study. Verbal and written informed consents were obtained from participants. Before the interview, with the permission of the participant, the mp3 device was turned on and the recording was started. Prior to that, the participant was assured that his/her audio file would not be available to anyone other than the researcher, his/her words would be used only for study, and the results would be given without mentioning the name and only mentioning a number. The data were managed confidentially, and the findings were reported honestly. All of the audio files of the participants, as well as texts transcribed in Microsoft office word, were written to a DVD and stored in a secure and locked cabinet in the researcher's office, and will eventually be destroyed.

\section{Consent for publication}

Not applicable.

\section{Availability of data and material}

All the raw data (participants' voice files and the texts of the interviews) will be confidential and cannot be provided to anyone. However, the codes emerged during the current study are available from the corresponding author on reasonable request.

\section{Competing interests}

The authors declare that they have no competing interests.

\section{Funding}

The funding was provided by the Kashan Medical Science University under the grant number 98175 .

\section{Authors' contributions}

$\mathrm{M}-\mathrm{AH}$ and $\mathrm{M}-\mathrm{Z}$ supervised all stages of data collection and data analysis and provided critical points during the manuscript preparation. 
SH-B performed the study conception, data collection and analysis and wrote the first draft of the manuscript.

\section{Acknowledgments}

This study is a part of a nursing doctoral dissertation and a research project approved by kashan University of Medical Sciences. The authors appreciate all the authorities in kashan University of Medical Sciences supported this research. The authors also thank of all nurses, supervisors and nurse managers who participated in this study.

\section{References}

1. Yadegary MA, Aghajanloo A, Negarandeh R. Challenges of professional self-regulation in Iranian nursing Hayat. 2017;23(1):1-6.

2. Shareinia $H$, Khodadadi $E$, Nedaei $H$, Hosseini M. Professional and ethical values in providing nursing care from nurses' perspective. Iran Journal of Nursing. 2018;31(112):44-55.

3. Rassin M. Nurses' professional and personal values. Nursing ethics. 2008;15(5):614-30.

4. Parvan K, Zamanzadeh V. Professional values of the nursing students' perspective in type 1 universities of medical sciences. Quarterly Journal of Nursing Management. 2012;1(1):69-82.

5. Rivero DE, Erdmann AL. The power of loving humane care in nursing. Revista latino-americana de enfermagem. 2007;15(4):618-25.

6. Emakpor C, Nyback M-H. Love; a relevant concept in nursing and caring science. Novia University of Applied Sciences, Tehtaankatu 1, Vaasa, Finland. 2010:1-15.

7. Watson J. Love and caring: Ethics of face and hand-An invitation to return to the heart and soul of nursing and our deep humanity. Nursing administration quarterly. 2003;27(3):197-202.

8. 8.

9. Sayed S, Ahmed A, Bakr M, Sherief N. Work Engagement in Nursing: A concept Analysis. Menoufia Nursing Journal. 2019;4(1):13-8.

10. Wang S, Liu Y. Impact of professional nursing practice environment and psychological empowerment on nurses' work engagement: test of structural equation modelling. Journal of Nursing Management. 2015;23(3):287-96.

11. Arman M, Rehnsfeldt A, editors. The presence of love in ethical caring. Nursing forum; 2006: Wiley Online Library.

12. Babaei khalaji M, Ahmadi SAA, Shahbazi M. Investigation of the Effective Factors on Employee Engagement of Nurses in Farabi Eye Hospital affiliated to Tehran University of Medical Sciences. Journal of public administration (management knowledge). 2014;5(4):39-56.

13. Cheraghi M, Javaheri F. Neuman theory application in solution of Iranian nursing education and care challenges. Iranian Journal of Systematic Review in Medical Sciences. 2020;1(1):1-14. 
14. Adib-Hajbaghery M, Zehtabchi S, Fini IA. Iranian nurses' professional competence in spiritual care in 2014. Nursing Ethics. 2017;24(4):462-73.

15. Adib-Hajbaghery M, Bolandian-Bafghi S, Zandi M. Nurses' Perceptions of the Factors Contributing to the Development of the Love of the Profession: A Qualitative Content Analysis. Nursing Reports. 2021;11(3):702-13.

16. Abaszadeh A, Borhani F. Factors affecting discipline (Major) choice among newly admitted students of nursing in Kerman university of medical sciences. Iranian Journal of Medical Education. 2012;11(6):600-8.

17. Russo M, Buonocore F. The relationship between work-family enrichment and nurse turnover. Journal of Managerial Psychology. 2012;27(3):236-16.

18. Amor AM, Vázquez JPA, Faíña JA. Transformational leadership and work engagement: Exploring the mediating role of structural empowerment. European Management Journal. 2020;38(1):169-78.

19. Rivera RR, Fitzpatrick JJ, Boyle SM. Closing the RN engagement gap: which drivers of engagement matter? JONA: The Journal of Nursing Administration. 2011;41(6):265-72.

20. Graneheim UH, Lundman B. Qualitative content analysis in nursing research: concepts, procedures and measures to achieve trustworthiness. Nurse education today. 2004;24(2):105-12.

21. Mack N, Woodsong C, Macqueen K, Guest G, Namey E. Qualitative Research Methods: A Data Collector's Field Guide: Research Triangle Park, NC: Family Health International; 2005.

22. Abbaszadeh M. Validity and reliability in qualitative researches. journal of applied sociology. 2012;23(1):19-34.

23. Bitsch V. Qualitative research: A grounded theory example and evaluation criteria. Journal of agribusiness. 2005;23(345-2016-15096):7591-.

24. Heshmati Nabavi F, Shakeri MT, Hoseinpur Z. Comparing shaping resources of the nursing public image and their importance from the perspective of nurses and general public. Quarterly Journal of Nursing Management. 2014;3(1):8-18.

25. Bahrami M, Rahimzadeh-Feyzabad T. The relationship between social and professional status and occupational components from the nurses' perspective in Vali-e Asr Educational Hospital of Birjand. Beyhagh. 2017;22(40):50-9.

26. Valizadeh S, Haririan H. Nurses Work Motivation: A Big Challenge for Health System; a Review article. Preventive Care in Nursing Midwifery Journal. 2016;5(2):56-64.

27. Sadat Hosseini AS, Z V. The effect of gender on nursing. ijme. 2012;5(1):71-81.

28. Ndirangu EW, Sarki AM, Mbekenga C, Edwards G. Professional image of nursing and midwifery in East Africa: an exploratory analysis. BMC nursing. 2021;20(1):1-11.

29. Christman LP. Heroism as a nursing value. Nursing Administration Quarterly. 1982;6(3):85-6.

30. MacDonald K, De Zylva J, McAllister M, Brien DL. Heroism and nursing: A thematic review of the literature. Nurse education today. 2018;68:134-40. 
31. Bennett CL, James AH, Kelly D. Beyond tropes: Towards a new image of nursing in the wake of COVID-19. Journal of Clinical Nursing 2020:3-1.

32. Sun N, Wei L, Shi S, Jiao D, Song R, Ma L, et al. A qualitative study on the psychological experience of caregivers of COVID-19 patients. American journal of infection control. 2020;48(6):592-8.

33. Namdari S, Nasiri A, Nakhaee S, Taheri F. Exploring the effects of nurses' family-work conflict on patient care quality: a qualitative study. Modern Care Journal. 2019;16(1):6-1.

34. Tabataba'i-Nasab SM, Sabokro M, Fallahi MB. The effect of psychological capital on work engagement with mediating role of work-family conflict among nurses. Quarterly Journal of Nursing Management. 2017;6(1):20-31.

35. Makola L. Work-family and family-work conflicts amongst nurses working with HIV/AIDS patients within the Limpopo Province (Capricorn and Mopani Districts): University of Limpopo (Turfloop Campus); 2014.

36. Caricati L, Sala RL, Marletta G, Pelosi G, Ampollini M, Fabbri A, et al. Work climate, work values and professional commitment as predictors of job satisfaction in nurses. Journal of nursing management. 2014;22(8):984-94.

37. Vardaman JM, Allen DG, Otondo RF, Hancock JI, Shore LM, Rogers BL. Social comparisons and organizational support: Implications for commitment and retention. Human relations. 2016;69(7):1483-505.

38. Venkataramani V, Labianca GJ, Grosser T. Positive and negative workplace relationships, social satisfaction, and organizational attachment. Journal of applied psychology. 2013;98(6):1028.

39. Dasgupta P. Work engagement of nurses in private hospitals: A study of its antecedents and mediators. Journal of Health Management. 2016;18(4):555-68.

40. Tran KT, Nguyen PV, Dang TT, Ton TN. The impacts of the high-quality workplace relationships on job performance: a perspective on staff nurses in Vietnam. Behavioral sciences. 2018;8(12):109.

41. Cho J, Laschinger HS, Wong C. Workplace empowerment, work engagement and organizational commitment of new graduate nurses. Nursing Leadership-Academy of Canadian Executive Nurses-. 2006;19(3):60-43.

42. Shekari H, MohammadiAhmadabadi N, Dehghani M, Afkhami Aghda M. Investigating the Effect of Organizational Health on Work Engagement among Nurses in Yazd Social Security Hospital. Tolooebehdasht. 2017;15(6):90-106. 